\title{
Coping strategies among adolescents with chronic headache and mental health problems: a cross-sectional population-based study
}

\author{
Silje Hartberg ${ }^{1,2^{*}}$, Jocelyne Clench-Aas ${ }^{5}$, Ruth Kjærsti Raanaas ${ }^{1}$ and Christofer Lundqvist ${ }^{2,3,4}$
}

\begin{abstract}
To examine prevalence of mental health problems among adolescents with chronic headache and compare internal and external coping strategies in young people with chronic headaches with and without mental health problems. This study is based on a cross-sectional survey undertaken in Akershus County in Norway. A total of 19,985 adolescents were included in the study, covering lower secondary and upper secondary students, aged 13-19 years. Chronic headache was measured with a single item question based on headache frequency. Mental health was assessed by using the strengths and difficulties questionnaire (SDQ). Internal and external coping strategies were assessed through seven options for answering the question: What do you do/what happens when you are burdened by painful thoughts and feelings? Adolescents with chronic headaches showed more frequent mental health problems overall (23\%) compared to those without chronic headache (6\%). Logistic regression analyses showed that those adolescents having both chronic headaches and comorbid mental health problems more frequently used internal coping strategies, such as keeping feelings inside (OR 2.05), using abusive substances (OR 1.79) and talking oneself out of problems (OR 1.55), compared to those without mental health problems. Groups with mental health problems, especially with chronic headache, less frequently used the external strategy of talking to others about their problem than controls (OR 0.7-0.8). Factor analyses revealed significant differences in profiles of coping strategies between groups. We suggest that attention should be paid towards the high risk group that has both chronic headaches and mental health problems and their tendency to use destructive internal coping strategies.
\end{abstract}

Keywords: Mastery, Tension type headache, Migraine, Young adults/students,

Strengths and difficulties questionnaire

\section{Background}

Headache disorders are among the top ten causes of disability in Europe (Steiner and Martelletti 2007; Steiner et al. 2015). Chronic headache is a major problem in children and adolescents (Gladstein 2004; Guidetti et al. 2000). It is characterized by a high degree of psychiatric comorbidity (Guidetti 2002). Stovner and colleagues (2007) found that the worldwide prevalence of chronic

\footnotetext{
*Correspondence: shartberg@gmail.com

${ }^{2}$ Health Services Research Centre, Akershus University Hospital,

Lørenskog, Norway

Full list of author information is available at the end of the article
}

headache in the adult population was $3 \%$ [2.4\% in Norwegian adults (Stovner et al. 2006)]. In children the prevalence ranges from 0.9 to $7.8 \%$ worldwide (Seshia et al. 2010).

For children and adolescents who experience headache problems, psychological issues are well-recognized, but poorly understood clinical phenomena (Powers et al. 2006). The presence of psychiatric comorbidity is associated with poorer prognosis, decreased quality-of-life (Baskin et al. 2006) and increased psychosocial problems (Powers et al. 2006). Several studies suggest a bi-directional relationship between the comorbidity of headache and psychiatric disorders (Gentili et al. 2005; Wang and

\section{Springer}

(c) 2015 Hartberg et al. This article is distributed under the terms of the Creative Commons Attribution 4.0 International License (http://creativecommons.org/licenses/by/4.0/), which permits unrestricted use, distribution, and reproduction in any medium, provided you give appropriate credit to the original author(s) and the source, provide a link to the Creative Commons license, and indicate if changes were made. 
Juang 2002). Pompili and colleagues (2010) found that the relationship between migraine and psychopathology has not been systematically studied and suggested that future research should focus on the interplay of factors behind the relationship between migraine, suicide risk and mental illness. In the general population, on the other hand, because of relative low frequency of chronic migraine (Krogh et al. 2015), it is more interesting to study the relation between tension type headache and mental illness. However, studies suggest that psychopathology may be more linked to frequency of headache than to a specific headache diagnosis (Blaauw et al. 2015).

Coping has been defined as "constantly changing cognitive and behavioural efforts to manage specific external and/or internal demands that are appraised as taxing or exceeding the resources of the person" (Lazarus and Folkman 1984). It is described as "an ongoing dynamic process that changes in response to the changing demands of a stressful encounter or event" and as a "purposeful response [...] directed towards resolving the stressful response between the self and the environment (problem focused coping) or toward $[\ldots]$ negative emotions that arise as a result of stress (emotion-focused coping)" (Lazarus and Folkman 1984). In addition to this description, coping strategies have been described along axes such as "internal-external", "voluntary-involuntary", "engagement-disengagement" and "primary-secondary" (Lazarus and Folkman 1984; Compas et al. 2001). Though there is disagreement regarding the most constructive way to describe different ways of coping, some strategies have, nevertheless, been suggested to be more related to good mental health than others (Holen et al. 2012). This may be of importance regarding both diagnosis and treatment of disorders related to mental health and handling of stress and pain. The present study utilizes an internal vs. external coping strategy axis system (Lazarus and Folkman 1984; Pratt et al. 1985). This is based on the notion that some external strategies may be more strongly related to good mental health, as they are based on the individual seeking solutions outside him/herself e.g. through communication seeking external help in identifying and solving the problem. Internal strategies, on the other hand, involve efforts to regulate the emotional distress through internal efforts e.g. by venting negative emotions, using drugs/alcohol in attempts to attenuate the experienced distress and denying the association between the stressor and the experience (Jorgensen and Dusek 1990). Some internal strategies may be perceived as similar to avoidance strategies or withdrawal, which have been suggested to represent poor adaptation. This has been observed mainly in children and adolescents with depressive or anxiety symptoms (Holen et al. 2012; Chan 1995; Seiffge-Krenke 2000). An additional reason for choosing this categorization is that, in a treatment perspective the use of external strategies may be more accessible for therapy while internal coping may be more difficult to assess and influence.

In the field of headache, it is well established that chronic and frequent headache is associated with depressive symptoms and symptoms of anxiety as well as with more stressful life events (Wittrock and Myers 1998). In addition, headache patients have been suggested to use more maladaptive coping strategies (Wittrock and Myers 1998). Such coping patterns may especially involve the more internal coping strategies of avoidance and dissimulation (Wittrock and Myers 1998; Rollnik et al. 2001). Regarding coping patterns among youngsters with headache, studies have suggested such maladaptive strategies to be used more commonly among children and adolescents with headaches (Lanzi et al. 2001). Experimental studies have demonstrated that internalising strategies such as avoidance lead to increased distress while distraction, representing a more externalising coping behaviour decreases the level of distress, however, there are gaps in knowledge on coping and mental health problems in chronic headache among adolescents [(Compas et al. 2001) for review].

The present study aims to describe the prevalence and impact of chronic headache and mental health problems in adolescents using a well validated scale, the strength and difficulties questionnaire (SDQ) among a large representative $(\mathrm{N}=19,985)$ sample of adolescents living in Norway. In addition, the aim was to compare the coping strategies favored by the different groups within an internal and external coping strategy framework.

\section{Methods}

\section{Design and participants}

This cross-sectional health survey was undertaken in Akershus County, Norway, an area including urban, suburban and rural areas, with clear differences in socio-economic status among the inhabitants.

Whole classes of pupils were selected to participate from randomly selected classes and schools in the county. The study included a total of 19,985 pupils from lower secondary school $(\mathrm{n}=9414)$ and upper secondary school $(n=10,571)$, aged $13-19$ years. The total response percentage was 82. Questionnaires were filled out at school, under the supervision of the teacher. A letter asking for parental consent with one reminder was sent to parents, prior to the study. The pupils that were invited to the study but did not participate, were primarily either home from school, on a school-trip or their teacher was off work. 


\section{Measures}

Four health groups were defined based on the two dependent variables chronic headaches and mental health problems. The groups were: "chronic headaches without mental health problems" $(\mathrm{CH})$, "chronic headaches with simultaneous mental health problems" (CHMH), "mental health problems without chronic headaches" (MH) and a control group with neither chronic headache, nor mental health problems. The statistical analyses were done as a multinomial logistic analysis, with presence of each of the above defined health groups set as the dependent variable.

Chronic headache was assessed by the question "During the past 6 months, how often have you had the following complaints", where headache is included as one of the complaints. The response possibilities were "almost every day", "more than once a week", "about every week", "about every month", "seldom or never". "Almost every day" was defined as chronic headache in close accordance with the definition of chronic headaches according to the International Classification of Headache disorders, version 2 with chronic headache defined as more than half of the days with headache (Olesen and Steiner 2004).

Mental health problems were assessed using The strengths and difficulties questionnaires (SDQ) (Goodman 2011). We used four of the five original SDQ symptom scales, each with five items: emotional, conduct, hyperactivity and peer problems. The question about headache symptoms in the emotional subscale was excluded to avoid confounding the exposure (headache) and the outcome (SDQ). Each item has a threepoint response scale $(0=$ not true, $1=$ somewhat true, 2 = certainly true). Responses were rated 2 to 0 for positively worded items, and inversely coded for negatively worded items. The three subscales with five items each were summed to get a maximum total score of 10 , whereas the emotion subscale with the headache question removed, summed to a maximum of 8 . A total difficulties score was thus calculated based on adding the first four subscales scores, giving a total ranging from 0 to 38 . It has previously been recommended to define three population groups (Goodman 2011); normal (lowest $80 \%$ of population), borderline (10\%) and abnormal/caseness (highest $10 \%$ ). Further, Van Roy (2008) redefined the cut-offs to correspond to Norwegian symptom reporting, keeping the suggested 80-10-10 distribution. Since we removed one question from the SDQ, we redefined cut-off points for the normal group as $0-15$, borderline scores from 16 to 19 and the abnormal group with scores from 20 to 38, corresponding as close to the Norwegian $80-10-10$ cut-offs as possible (Van Roy et al. 2008). These values were for logistic regression further dichotomised into normal versus borderline/abnormal, which is a standard method of analysis (Goodman 2011).

To assess the impact of the mental health problem in everyday life, the extended version of the SDQ was used including five questions concerning overall distress and social impairment. Responses were coded into $0=$ no/little, 1 = quite a lot, 2 = a great deal. The five items generate an impact score, ranging from 0 to 10 . A total impact score of 1 is defined as borderline, and a score of 2 or more defines abnormal/caseness (Goodman 2011). These values were for logistic regression further dichotomised into normal versus borderline/abnormal. We decided to restrict the definition of mental health problems to those exhibiting both symptoms of problems as measured by the SDQ symptom score, and additionally showing indications of overall distress and social impairment. Thus a new variable was made that summed the dichotomous symptom score and the dichotomous impact score (Goodman 2011). The resulting variable was further dichotomised. To qualify as having a mental health problem, the participants thus had to be borderline or abnormal for both the total symptom score and the impact score. The Cronbach's alpha for the 19 questions of SDQ total symptoms excluding the headache question was found to be 0.78 .

Coping strategies were assessed by the scenario: "What do you do/what happens when you are burdened by painful thoughts and feelings?" We used seven items (Table 1$)$, each with three categorical answers $(0=$ not true, $1=$ somewhat true and $2=$ certainly true). We divided coping into four internal (ICS1, ICS2, ICS3 and ICS4) and three external (ECS1, ECS2 and ECS3) coping strategies (see Table 1). These were treated as independent variables. The correlation between the coping variables was tested by Pearson's $r$ and found not to be substantial, ranging from 0 to 0.28 . Confounders adjusted for in the analyses were gender, grade, socioeconomic status, living with both parents or not, subjective schoolrelated stress and nation of origin (separated as western or non-western). For the variable coping strategies, missing data ranged between 937 and 1459 of the total number $(19,985)$.

\section{Ethics}

Participation was voluntary, all questionnaires were anonymous, and based on individual informed consent. Pupils in secondary schools had parental consent. The health survey was conducted after approval from the Regional Ethics Committee.

\section{Statistical analyses}

All preliminary analyses were performed by the Statistical Package for Social Sciences (SPSS) version 22.0. 
Table 1 List of coping strategies [internal (ICS) and external (ECS) coping strategies]

\begin{tabular}{llr}
\hline & & N (\%) \\
\hline ICS 1_Keep painful thoughts and feelings inside & No & $15,875(84.5)$ \\
& Yes & $2919(15.5)$ \\
ICS 2 -Work more with other things to avoid think- & No & $14,106(75.3)$ \\
ing bad thoughts & Yes & $4615(24.7)$ \\
ICS 3_Using abusive substances when having bad & No & $17,809(95.8)$ \\
thoughts or feelings & Yes & $772(4.2)$ \\
ICS 4-Try to talk oneself out of problems & No & $16,574(89.0)$ \\
& Yes & $2044(11.0)$ \\
ECS 1-Visit health care service when having bad & No & $18,225(98.4)$ \\
thoughts or feelings & Yes & $301(1.6)$ \\
ECS 2-Speak with family when having bad & No & $14,256(75.6)$ \\
thoughts or feelings & Yes & $4600(24.4)$ \\
ECS 3 -Speak with friends when having bad & No & $9355(49.1)$ \\
thoughts or feelings & Yes & $9693(50.9)$ \\
\hline
\end{tabular}

No is defined as either not true or somewhat true, whereas yes is equivalent to certainly true

Confirmatory factor analysis (CFA) operations were then conducted using maximum likelihood (ML) estimation by means of Analysis of Moment Structures (AMOS version 22) (Arbuckle 2013).

Multinomial logistic regression analyses were used to estimate the associations between chronic headache and mental health groups $(\mathrm{CH}, \mathrm{CHMH}, \mathrm{MH})$ and the independent variables as compared to the control group. The analyses were stratified by health group. All analyses were controlled for age, gender, socioeconomic status, living with both parents or not, subjective school-related stress and nation of origin. Due to a complex sampling design with county and class as unit, logistic regression analyses were performed using the SPSS module, complex samples, which corrects estimates of standard errors accounting for sampling design (Osborne 2011). Odds ratio [with $95 \%$ confidence interval (CI)] was used to estimate outcome, for multiple comparisons Bonferroni corrected $\mathrm{p}$ values $(\mathrm{p}<0.0017)$ were used to avoid the risk of mass significance. Cases were removed if at least one variable was missing (listwise deletion). The significance level was set to $\mathrm{p}<0.05$ and effect estimates reported Beta with SE. All variables were checked for multicollinearity. Tolerance should not be above 0.10 and VIF should be below 10 (Pallant 2010). These assumptions were not violated for any variables in the analyses.

To evaluate the coping strategy profiles, we performed CFAs (Bollen 2014) using data from each of the different subgroups. The analyses were run by means of ML estimation.

As the $\chi^{2}$ has been shown to be problematic for assessing model fit in large samples (Byrne 2013; Cheung and
Rensvold 2002; Hirschfeld and von Brachel 2014; Hooper et al. 2008), model fit was primarily assessed using the root mean square error of approximation (RMSEA) with values of $0.08,0.05$ and 0 , and the comparative fit index (CFI), with values $0.90,0.95$ and 1.0 demonstrating reasonable, close and exact fit, respectively.

Invariance testing was conducted by multi-group CFAs using ML estimation in AMOS 22. This method employs successive analyses where constraints to the models are added consecutively. We used the baseline, unconstrained model, with one factor loading constrained to unity. Good model fit at this stage and significant factor loadings is indicative of configural invariance (Hirschfeld and von Brachel 2014). In addition, the weak (metric) model was used. Invariance at this level implies that the regression slopes are invariant across groups and implies that the same latent variables are being measured across groups. $\triangle$ CFI was used with a cut-off $\leq 0.01$ indicating invariance between subgroups (Byrne 2013; Hirschfeld and von Brachel 2014; Hooper et al. 2008; Meade et al. 2008).

\section{Results}

\section{Prevalence}

To test for representativity of the sample, the prevalence of some of the control variables were compared to national averages for 2002 (Statistics Norway 2015). The results indicated that there were identical prevalence of males and females $(\mathrm{M}=51 \% ; \mathrm{F}=49 \%)$ in both sample and national values; nearly identical prevalence of those with Norwegian national identity $(84.7 \%$ nationwide versus 84.6 in this sample); while prevalence of those living with both parents was slightly higher in the sample $(67.5 \%)$ than the nationwide values of $62.1 \%$.

$3.7 \%$ of participants $(\mathrm{n}=717)$ met the criteria for $\mathrm{CH}$, $1.1 \%(\mathrm{n}=212)$ for $\mathrm{CHMH}$ and $5.5 \%(\mathrm{n}=1049)$ for $\mathrm{MH}$, whereas $89.7 \%$ are in the control group $(\mathrm{N}=17,143)$ (thus a total $\mathrm{N}=19,121$ after missing values for disease criteria were removed). Of the 929 adolescents with chronic headaches, $23 \%$ thus had comorbid mental health problems compared with a $5.8 \%$ prevalence of mental health problems among those without chronic headache. The relative risk (RR) of having chronic headaches when also having mental health problems was 4.2 (95 \% CI: 3.6-4.8) while the RR of having mental health problems when also having chronic headaches was 4.0 (95 \% CI: 3.5-4.5). Tables 2 and 3 show the prevalence of the demographic variables and the coping strategies in the three groups: $\mathrm{CH}, \mathrm{CHMH}$ and $\mathrm{MH}$.

\section{Chronic headaches without mental health problems}

There was a relationship between having chronic headaches, and using the internal coping strategies of keeping 
Table 2 Comparison of coping strategies [internal (ICS) and external (ECS) coping strategies] between headache and mental health groups

\begin{tabular}{|c|c|c|c|c|c|}
\hline & & Control N (\%) & CH N (\%) & CHMH N (\%) & MH N (\%) \\
\hline \multirow[t]{2}{*}{ ICS 1-Keep painful thoughts and feelings inside } & No & $14,202(86.8)^{a}$ & $510(75.8)^{c}$ & $94(46.5)^{d}$ & $643(63.9)^{b}$ \\
\hline & Yes & $2155(13.2)^{\mathrm{a}}$ & $163(24.2)^{c}$ & $108(53.5)^{d}$ & $363(36.1)^{b}$ \\
\hline \multirow[t]{2}{*}{ ICS 2-Work more with other things to avoid thinking bad thoughts } & No & $12,475(76.3)^{\mathrm{a}}$ & $464(69.8)^{b}$ & $131(65.8)^{b}$ & $668(68.0)^{b}$ \\
\hline & Yes & $3868(23.7)^{\mathrm{a}}$ & $201(30.2)^{b}$ & $68(34.2)^{b}$ & $314(32.0)^{b}$ \\
\hline \multirow[t]{2}{*}{ ICS 3-Using abusive substances when having bad thoughts or feelings } & No & $15,727(97.0)^{\mathrm{a}}$ & $598(92.0)^{c}$ & $160(79.2)^{d}$ & $862(86.5)^{b}$ \\
\hline & Yes & $489(3.0)^{\mathrm{a}}$ & $52(8.0)^{c}$ & $42(20.8)^{d}$ & $134(13.5)^{b}$ \\
\hline \multirow[t]{2}{*}{ ICS 4-Try to talk oneself out of problems } & No & $14,756(90.8)^{\mathrm{a}}$ & $520(78.8)^{b}$ & $124(61.4)^{c}$ & $745(74.9)^{b}$ \\
\hline & Yes & $1502(9.2)^{\mathrm{a}}$ & $140(21.2)^{b}$ & $78(38.6)^{c}$ & $249(25.1)^{b}$ \\
\hline \multirow[t]{2}{*}{ ECS 1-Visit health care service when having bad thoughts or feelings } & No & $15,999(98.8)^{\mathrm{a}}$ & $629(96.3)^{b}$ & $183(91.5)^{c}$ & $949(95.6)^{b, c}$ \\
\hline & Yes & $199(1.2)^{\mathrm{a}}$ & $24(3.7)^{b}$ & $17(8.5)^{c}$ & $44(4.4)^{\mathrm{b}, \mathrm{c}}$ \\
\hline \multirow[t]{2}{*}{ ECS 2-Speak with family when having bad thoughts or feelings } & No & $12,308(74.9)^{\mathrm{a}}$ & $519(77.8)^{\mathrm{a}, \mathrm{c}}$ & $171(85.5)^{b, c}$ & $873(87.2)^{b}$ \\
\hline & Yes & $4123(25.1)^{a}$ & $148(22.2)^{\mathrm{a}, \mathrm{c}}$ & $29(14.5)^{b, c}$ & $128(12.8)^{b}$ \\
\hline \multirow[t]{2}{*}{ ECS 3-Speak with friends when having bad thoughts or feelings } & No & $8004(48.2)^{a}$ & $320(47.6)^{a}$ & $128(64.0)^{b}$ & $627(62.2)^{b}$ \\
\hline & Yes & $8592(51.8)^{a}$ & $352(52.4)^{a}$ & $72(36.0)^{b}$ & $381(37.8)^{b}$ \\
\hline
\end{tabular}

No is defined as either not true or somewhat true, whereas yes is equivalent to certainly true

Values in the same row and subtable not sharing the same superscript are significantly different at $p<0.05$ in the two-sided test of equality for column proportions. Tests assume equal variances (tests are adjusted for all pairwise comparisons within a row of each innermost subtable using the Bonferroni correction)

troubles inside, and using abusive substances when bad thoughts and feelings create pressure (Table 4).

The $\mathrm{CH}$ group also tended to use the internal coping strategy of talking themselves out of their problems, and the external coping strategy of visiting health care services, more so than the control group. The $\mathrm{CH}$ subjects were less likely to use the external coping strategies of speaking with friends or family compared with the control group. The rank order of odds ratios for coping strategies used more by the $\mathrm{CH}$ group was: visit health care services $>$ using abusive substances $>$ talk oneself out of problems $>$ keeping painful thoughts or feelings inside.

\section{Chronic headaches with simultaneous mental health problems}

The $\mathrm{CHMH}$ subjects were more than two times more likely to use the internal coping strategies of keeping painful thoughts or feelings inside, using abusive substances and talking themselves out of their problems than the control group (Table 4). The probability was two times higher for using the external coping strategy of visiting health care services when bad thoughts and feelings were present among the $\mathrm{CHMH}$ group, compared with the control group. In comparison with the $\mathrm{CH}$ group, the $\mathrm{CHMH}$ group was significantly more likely to use the internal coping strategies of keeping painful thoughts or feelings inside, using abusive substances and talking oneself out of problems. The $\mathrm{CHMH}$ group was also less likely to use the internal coping strategy of working more with other things. The $\mathrm{CHMH}$ group tended to use the external coping strategy of speaking with family less compared with the $\mathrm{CH}$ group (not significant) (Table 4). The rank order of odds ratios for coping strategies used more by this group was: keep painful thoughts or feelings inside $>$ using abusive substances $>$ visit health care service $>$ talk oneself out of problems. Speaking with others (both friends and family) and doing other things were little used strategies in this group.

\section{Mental health problems without chronic headaches}

The $\mathrm{MH}$ group used the internal coping strategy of keeping painful thoughts or feelings inside to a greater extent, compared with the control group (Table 4). The odds of using abusive substances as a coping strategy increased by a factor of 1.9 in the $\mathrm{MH}$ group, compared with the control group. There was a tendency among the $\mathrm{MH}$ group to use the external coping strategies of talking themselves out of problems, and seeking help from health care services when bad thoughts and feelings were present, compared to the control group. The rank order of odds ratios used more by this group was: using abusive substances $>$ talk oneself out of problems $>$ visit health care service > keep painful thoughts or feelings inside. Speaking with others (friends and family) was also here a less used strategy than in the control population.

\section{Effects of demographic variables on main outcomes (Table 3)}

Proportion of adolescents classified as $\mathrm{CH}$ or $\mathrm{CHMH}$ significantly decreased with increasing age, whereas 
Table 3 Prevalence (\%) of background variables and independent variables in the groups: control group $\mathrm{CH}, \mathrm{MH}$ and $\mathrm{CHMH}$

\begin{tabular}{|c|c|c|c|c|}
\hline & Control group & $\mathrm{CH}$ & $\mathrm{CHMH}$ & MH \\
\hline \multicolumn{5}{|l|}{ Sex } \\
\hline Boy & $52.0^{\mathrm{a}}$ & $30.4^{c}$ & $31.9^{c}$ & $41.8^{b}$ \\
\hline Girl & $48.0^{\mathrm{a}}$ & $69.6^{c}$ & $68.1^{c}$ & $58.2^{\mathrm{b}}$ \\
\hline \multicolumn{5}{|l|}{ Grade } \\
\hline 8th grade LSS & $17.3^{\mathrm{a}}$ & $16.8^{a, c}$ & $10.0^{b, c}$ & $11.9^{b}$ \\
\hline 9th grade LSS & $15.7^{\mathrm{a}}$ & $16.2^{\mathrm{a}}$ & $19.0^{\mathrm{a}}$ & $15.1^{\mathrm{a}}$ \\
\hline 10th grade LSS & $14.5^{\mathrm{a}}$ & $14.1^{\mathrm{a}}$ & $13.3^{\mathrm{a}}$ & $12.8^{\mathrm{a}}$ \\
\hline 1st grade USS & $24.2^{\mathrm{a}}$ & $27.1^{\mathrm{a}, \mathrm{b}}$ & $29.9^{a, b}$ & $27.8^{\mathrm{b}}$ \\
\hline 2nd grade USS & $16.6^{\mathrm{a}}$ & $14.7^{\mathrm{a}}$ & $18.0^{\mathrm{a}}$ & $18.2^{\mathrm{a}}$ \\
\hline 3rd grade USS & $11.7^{\mathrm{a}}$ & $11.0^{\mathrm{a}}$ & $10.0^{\mathrm{a}}$ & $14.2^{\mathrm{a}}$ \\
\hline \multicolumn{5}{|l|}{ How well off is your family? } \\
\hline Very good & $13.3^{\mathrm{a}}$ & $14.5^{\mathrm{a}}$ & $11.8^{\mathrm{a}}$ & $11.1^{\mathrm{a}}$ \\
\hline Good & $48.9^{\mathrm{a}}$ & $41.7^{c}$ & $27.0^{\mathrm{b}}$ & $32.0^{\mathrm{b}}$ \\
\hline Medium & $31.2^{\mathrm{a}}$ & $30.6^{\mathrm{a}}$ & $37.9^{a, b}$ & $37.0^{\mathrm{b}}$ \\
\hline Not very good & $5.4^{\mathrm{a}}$ & $9.7^{b}$ & $12.3^{\mathrm{b}}$ & $13.6^{b}$ \\
\hline Poorly & $1.1^{\mathrm{a}}$ & $3.4^{c}$ & $10.9^{b}$ & $6.3^{b}$ \\
\hline \multicolumn{5}{|l|}{ Lives with both parents } \\
\hline Yes & $69.1^{\mathrm{a}}$ & $60.4^{c}$ & $51.2^{\mathrm{b}, \mathrm{c}}$ & $53.3^{b}$ \\
\hline No & $30.9^{a}$ & $39.6^{c}$ & $48.8^{b, c}$ & $46.7^{b}$ \\
\hline \multicolumn{5}{|c|}{ How stressed are you of school work? } \\
\hline Not at all & $11.5^{\mathrm{a}}$ & $7.5^{\mathrm{b}}$ & $8.6^{a, b}$ & $7.2^{b}$ \\
\hline A little & $47.1^{\mathrm{a}}$ & $28.5^{\mathrm{b}}$ & $18.6^{c}$ & $23.1^{b, c}$ \\
\hline Pretty much & $28.4^{\mathrm{a}}$ & $33.9^{\mathrm{b}}$ & $22.9^{\mathrm{a}}$ & $33.6^{b}$ \\
\hline Very much & $13.0^{\mathrm{a}}$ & $30.1^{\mathrm{b}}$ & $50.0^{c}$ & $36.1^{b}$ \\
\hline \multicolumn{5}{|l|}{ Nation of origin } \\
\hline $\begin{array}{l}\text { Western country (incl. } \\
\text { Norway) }\end{array}$ & $94.9^{\mathrm{a}}$ & $93.6^{a, b}$ & $93.9^{a, b}$ & $91.3^{b}$ \\
\hline Asia/Afrika/Latin America & $5.1^{\mathrm{a}}$ & $6.4^{a, b}$ & $6.1^{a, b}$ & $8.7^{b}$ \\
\hline
\end{tabular}

Values in the same row and subtable not sharing the same superscript are significantly different at $p<0.05$ in the two-sided test of equality for column proportions. Tests assume equal variances (tests are adjusted for all pairwise comparisons within a row of each innermost subtable using the Bonferroni correction)

LSS lower secondary school, USS upper secondary school

proportions with $\mathrm{MH}$ alone increased with age. Female gender was a significant factor associated with more frequent caseness in all three outcome groups. Living situation (i.e. living with both parents as opposed to not) was a significant factor associated with less frequent caseness in all three outcome groups. Socioeconomic status was a significant factor associated with more frequent $\mathrm{MH}, \mathrm{CH}$ and $\mathrm{CHMH}$ with decreasing family income. Experienced school stress was a significant factor associated with more frequent $\mathrm{MH}, \mathrm{CH}$ and $\mathrm{CHMH}$. Having a non-Western nation of origin was only significantly associated with higher $\mathrm{MH}$. These demographic parameters were used as possible confounders and were adjusted for in main outcome analyses.

\section{Coping strategy profiles in the different health groups}

The results of the Confirmatory Factor Analysis (CFA) for each group is shown in Fig. 1, which presents the standardized coefficients of the unconstrained model for the entire population. Table 5 presents the values for each of the subgroups, $\mathrm{MH}, \mathrm{CH}$ and $\mathrm{CHMH}$. Using abusive substances consistently loaded less on the latent variable "internal coping strategies" than the other three related variables. The relative weight of these remaining three internal strategies were much closer to each other for all groups. Keeping painful thoughts and feelings inside was most strongly related to being in the $\mathrm{CH}$ group. Among the factor loadings related to the latent variable, external coping strategy, the strongest loading for all groups was towards speaking with family. The groups differed substantially in loadings of the individual strategies. The model showed moderate fit. The differences in the pattern of internal and external strategies used by the four groups were significant as tested by invariance testing (data not shown) and using the value of $<0.01$ as cut-off for $\triangle \mathrm{CFI}$.

\section{Discussion}

The current study examined the relationship between chronic headaches and coping strategies in adolescents. Chronic headaches among youth were associated with a higher risk of having mental health problems and vice versa. Our results suggest that different coping strategies were used among the four groups. Mental health impact is similar in groups with mental health problems whether or not they have chronic headaches, while youth without mental health problems reported lower impact, closer to that of the control group.

The present study is based on a large sample size and the response rate was high (82\%). Akershus county in the south east part of Norway, where the study took place is representative for the nation as a whole compared to national data (Statistics Norway 2015). The questionnaire was aimed at a broad description of health in youth and was not specific to the disease category of chronic headaches. Therefore, respondents could not know the purpose of the present study, namely mapping chronic headache disorders in adolescents. Chronic headache was measured with one simple question about several complaints during the past 6 months where headache was one of the complaints. Based on this question, we do not get information about important aspects of the headache: duration of the headache and how strong the headache is. Furthermore, the quantification (number of days of headache per month) which is an important criterion in the classification of headache, is imprecise here. Thus we cannot claim to have precise clinical headache diagnoses as basis for our study. On the other hand, as stated 
Table 4 Multivariate logistic regression analysis examining the association between the three groups: $\mathrm{CH}, \mathrm{CHMH}, \mathrm{MH}$, and internal (ICS) and external (ECS) coping strategies

\begin{tabular}{|c|c|c|c|}
\hline Coping strategy (reference "not true") & $\begin{array}{l}\text { CH vs control } \\
\text { OR }(95 \% \mathrm{Cl})\end{array}$ & $\begin{array}{l}\text { CHMH vs control } \\
\text { OR }(95 \% \mathrm{Cl})\end{array}$ & $\begin{array}{l}\text { MH vs control } \\
\text { OR }(95 \% \mathrm{Cl})\end{array}$ \\
\hline $\mathbf{N}$ & 15,828 & 15,463 & 16,487 \\
\hline ICS 1-Keep painful thoughts and feelings inside (reference "not true") & $1.22(1.15-1.29)^{*}$ & $2.96(2.81-3.12)^{*}$ & $1.65(1.58-1.73)^{*}$ \\
\hline ICS 2-Work more with other things to avoid thinking bad thoughts & $1.07(1.05-1.08)^{*}$ & $0.80(0.76-0.84)^{*}$ & $0.93(0.89-0.98)$ \\
\hline ICS 3-Using abusive substances when having bad thoughts or feelings & $1.46(1.42-1.49)^{*}$ & $2.39(2.25-2.53)^{*}$ & $1.90(1.86-1.95)^{*}$ \\
\hline ICS 4-Try to talk oneself out of problems & $1.32(1.29-1.37)^{*}$ & $2.00(2.19-2.61)^{*}$ & $1.77(1.73-1.80)^{*}$ \\
\hline ECS 1-Visit health care service when having bad thoughts or feelings & $1.47(1.34-1.61)^{*}$ & $2.39(2.19-2.61)^{*}$ & $1.72(1.65-1.79)^{*}$ \\
\hline ECS 2-Speak with family when having bad thoughts or feelings & $0.83(0.80-0.86)^{*}$ & $0.68(0.64-0.73)^{*}$ & $0.70(0.66-0.74)^{*}$ \\
\hline ECS 3-Speak with friends when having bad thoughts or feelings & $0.82(0.78-0.85)^{*}$ & $0.69(0.67-0.71)^{*}$ & $0.66(0.64-0.68)^{*}$ \\
\hline
\end{tabular}

The three groups are all compared to the control group having neither $\mathrm{CH}$ or $\mathrm{MH}$. Analyses done with complex samples

Cell values are odds ratios with $95 \%$ confidence intervals

Controlled for sex, grade, socio-economic status, lives with both parents, school-related stress and nation of origin

ICS internal coping strategy, ECS external coping strategy

* $p \leq 0.0017$ significance limits based on pre-decided limits which are corrected for 28 multiple comparisons by dividing $p=0.05$ by 30

above, few if any headache studies have focused on coping strategies in the detail that we have here. The criteria used to define the presence of mental health problems were strengthened to require the simultaneous presence of both abnormal or borderline symptom score and impact in SDQ (Goodman 2001). Several studies show that SDQ is a useful and valid tool for identifying mental health complications among children and adolescents (Goodman 2011; Mathai et al. 2004). We have therefore chosen to use this tool though there is so far no consensus on the optimal instrument. Studies are ongoing which search for improved instruments for assessing relevant psychological factors in chronic headache such as the "stagnation scale" (Innamorati et al. 2015). As described in the introduction, the various axes for measuring coping strategies are thus under debate. Though our coping strategy questions are not validated against other measures, we suggest that they may nevertheless be useful as defined. This study is based on self-report, and there is no clinical validation of the answers. We have no information concerning use of medication in connection with headaches, which may be of importance in relation both to contact with health services and other internal versus external coping strategies. On the other hand, it is more difficult to assign a headache diagnosis in children, partly because of the paediatric age (Seshia et al. 2010) and different diagnostic methods that have been used, making comparison difficult (Lipton et al. 2011).

The 6-month prevalence of chronic headaches (3.7\%) was considerably higher than that found in other studies among young people (Seshia et al. 2010). Possible explanations for the discrepancy, as compared with our study, may be: (1) different definitions of chronic headache, (2) variations in measuring instruments, (3) variations in the specified time frame for the headache, and (4) older age group in our study (13-19 years). Our data are based on self-evaluation which may also contribute to this difference. In addition, smaller sample sizes may give more uncertain estimates. We found that the relative risk (RR) of having chronic headaches when having mental health problems and vice versa was about 4 . However, a crosssectional study such as ours cannot answer the "chicken and egg" issue, thus our results underline the need for prospectively designed studies with emphasis on prognosis and etiological factors.

The prevalence of mental health problems among those with chronic headaches was found to be $23 \%$. A study by Wang and colleagues (Wang et al. 2007) reported psychiatric disorders in almost half of the 121 Taiwanese school children aged 12-14 years with chronic headaches. Other studies have found psychiatric disorders in $64-90 \%$ of patients with chronic headaches (Puca 2000; Verri et al. 1998). Differences across studies in the prevalence of psychiatric comorbidity in patients with chronic headaches may be due to the measuring instrument used to define psychological functioning. However, compared with controls without chronic headache, our data show that the prevalence of mental health problems in youth with chronic headache is high. We have focused on a group of adolescents, who, in addition to having chronic headache complaints, also have psychological problems. Few studies have examined the differences in coping strategies in adolescents with chronic headaches with or without comorbid psychiatric disorders. Previous studies have found that patients with chronic headache show an overall avoidance coping pattern (Rollnik et al. 2001), associated with increased psychological problems (Seiffge-Krenke 2000). It is likely that adolescents are 

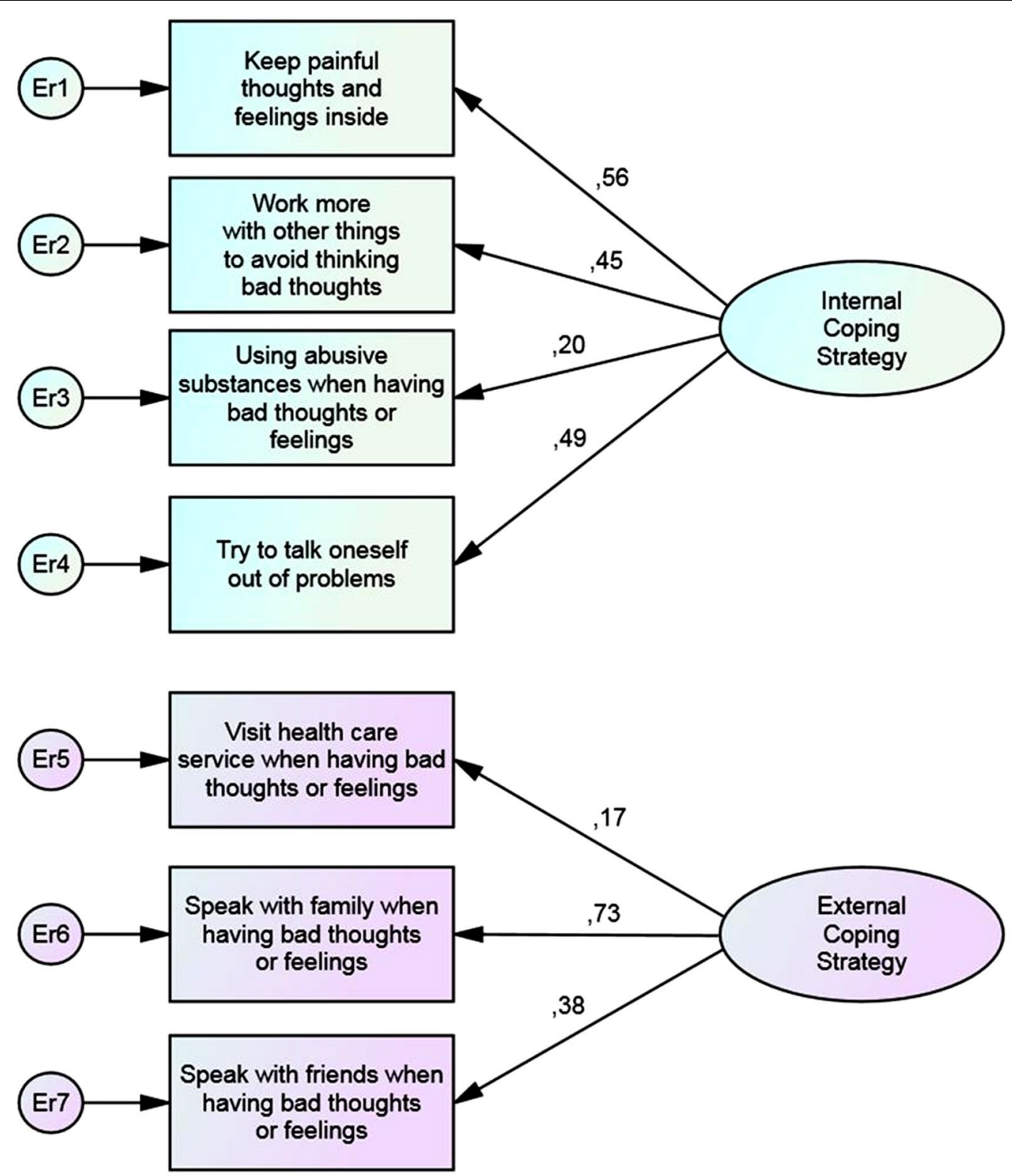

Fig. 1 Comparison of standardized factor loadings of individual coping strategies on latent internal (ICS) and external (ECS) coping strategies in the unconstrained model

even more inclined to use less mature coping strategies when having chronic headaches with comorbid mental health problems. This is in accordance with our study.

The CHMH group in the present study used internal coping strategies, to a larger degree than the two other groups. These findings are similar to Jorgensen and Dusek (Jorgensen and Dusek 1990), where less psychologically adjusted adolescents used less mature coping strategies like alcohol use and minimizing the problem to a greater degree. Ebata and Moos (Ebata and Moos 1991) had a similar finding in a longitudinal study of life stressors, social resources and coping among adolescents aged 12-18, where depressed adolescents and adolescents with conduct disorder used more avoidance coping mechanisms than healthy adolescents. In contrast, Murberg and Bru (Murberg and Bru 2005) did not find an effect of problem-focused coping strategies on symptoms of depression among Norwegian adolescents. Lanzi and colleagues (Lanzi et al. 2001) found that headache sufferers internalized their feelings, which to some extent may seem to support our findings. The $\mathrm{CH}$ group was more likely to use other strategies, compared to the $\mathrm{CHMH}$ 
Table 5 Standardized factor loadings for all seven items of coping strategies in a two factor model for each population subgroup $(N=19,121)$

\begin{tabular}{|c|c|c|c|c|}
\hline & Control & $\mathrm{CH}$ & $\mathrm{CHMH}$ & MH \\
\hline $\mathbf{N}$ & 17,143 & 717 & 212 & 1049 \\
\hline ICS 1-Keep painful thoughts and feelings inside & 0.53 & 0.60 & 0.48 & 0.44 \\
\hline ICS 2-Work more with other things to avoid thinking bad thoughts & 0.47 & 0.52 & 0.50 & 0.43 \\
\hline ICS 3-Using abusive substances when having bad thoughts or feelings & 0.14 & 0.15 & 0.12 & 0.13 \\
\hline ICS 4-Try to talk oneself out of problems & 0.45 & 0.48 & 0.42 & 0.50 \\
\hline ECS 1-Visit health care service when having bad thoughts or feelings & 0.18 & 0.30 & 0.23 & 0.28 \\
\hline ECS 2-Speak with family when having bad thoughts or feelings & 0.66 & 0.72 & 1.40 & 0.82 \\
\hline ECS 3-Speak with friends when having bad thoughts or feelings & 0.41 & 0.40 & 0.13 & 0.29 \\
\hline 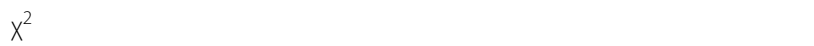 & 2870 & & & \\
\hline $\mathrm{CFI}$ & 0.615 & & & \\
\hline RMSEA & 0.051 & & & \\
\hline
\end{tabular}

ICS internal coping strategy, ECS external coping strategy, CFI comparative fit index, RMSEA root mean square error of approximation

group. According to Compas and colleagues (Compas et al. 2001), distraction decreased the levels of distress and intrusive thoughts. Thus our data suggests that the presence of mental health problems in adolescents with chronic headaches make the youth less able to distract themselves from troubled thoughts.

External coping strategies were used less commonly in the $\mathrm{CHMH}$ group compared to the control group with the exception of visiting health care services. Visiting health care services can be considered an external coping strategy, and contradicts studies saying that adolescents struggling with mental health problems show an overall coping strategy of avoidance (Chan 1995; Seiffge-Krenke 2000; Ebata and Moos 1991). This may, however, reflect the low threshold in Norway for visiting health units, since they are placed in or near schools. Speaking with family and friends were little used coping strategies in all groups, especially in the groups with mental health problems, and may reflect social isolation in adolescents struggling with mental health problems with or without chronic headaches. According to Martin and Theunissen (Martin and Theunissen 1993), adults with chronic headaches score significantly lower on social support, compared to non-headache subjects, which can be an indicator that chronic headache sufferers are less able to seek support from family or peers. The study by Murberg and Bru (Murberg and Bru 2005) found decreased levels of symptoms of depression in Norwegian adolescents that seek parental support in stressful situations. According to the latter study, the importance of the external coping strategies seeking parental or friend support are essential for mental health among adolescents. Our data suggests it may be even more important when having the additional burden of a chronic headache.

Categorising coping strategies into two dimensions, e.g. internal versus external coping, has been criticized
(Holen et al. 2012). It has been suggested that the studies do not adequately distinguish between the types of emotional coping strategies. Some found that a strategy based on emotion-focused coping is only related to risk if the use of other coping strategies is limited, others suggest that children who are flexible in their use of coping strategies have better mental health outcomes. The most recent studies on coping in children suggest that flexible use of three or more coping strategies may be advantageous (Holen et al. 2012). This study did indicate however, that coping strategy profiles used were significantly different between all groups.

\section{Conclusion}

In this study we have found that adolescents with chronic headaches show more frequent mental health problems than those without chronic headaches. The group of adolescents having both chronic headaches and mental health problems appear to be the most vulnerable population. Compared to adolescents without mental health problems, adolescents with chronic headaches that have simultaneous mental health problems, to a greater extent use internal coping strategies and to a lesser degree seek support in their social networks. Efforts should be made by school and health services, and in local communities to promote the use of external coping strategies in highrisk groups having both chronic headache and mental health problems. Exactly how this could be done requires further prospective, longitudinal follow-up studies of such issue-adapted treatment including a focus both on headache load, psychopathology and coping.

\section{Authors' contributions}

SH planned the overall project together with JCA and RKR, was responsible for the main data analysis and for preparing the first draft of the manuscript, JCA was responsible for the database and for the main support in the planning and execution of the statistical analyses of the data, RKR was the main tutor for 
$\mathrm{SH}$ throughout and contributed importantly with the population health perspective, $\mathrm{CL}$, whose main research focus is chronic headache and behavioural treatment, was involved in the planning of the project, supported in the analysis and was the senior main author of the paper. All authors contributed in the interpretation, editing of the final manuscript. All authors read and approved the final manuscript.

\section{Author details}

${ }^{1}$ Department of Landscape Architecture and Spatial Planning, Norwegian University of Life Sciences, Aas, Norway. ${ }^{2}$ Health Services Research Centre, Akershus University Hospital, Lørenskog, Norway. ${ }^{3}$ Department of Neurology, Akershus University Hospital, Lørenskog, Norway. ${ }^{4}$ Institute of Clinical Medicine, Campus Akershus University Hospital, University of Oslo, Nordbyhagen, Norway. ${ }^{5}$ Division of Mental Health, Department of Health Surveillance and Prevention, Norwegian Institute of Public Health, Oslo, Norway.

\section{Acknowledgements}

We thank the Norwegian Foundation for Health and Rehabilitation for financial support to the Health survey this study is based on. The Health survey was performed in cooperation with the Norwegian Service Research Centre, now incorporated in the Norwegian Knowledge Centre for Health Services. This research was made possible by the Department of Health Surveillance and Prevention at the Norwegian Institute of Public Health, which gave us access to their data and enabled us to perform this analysis.

\section{Competing interests}

The authors declare that they have no competing interests.

Received: 16 October 2015 Accepted: 8 December 2015

Published online: 22 December 2015

\section{References}

Arbuckle JL (2013) IBM SPSS Amos 22 user's guide. Amos Development Corporation, Crawfordville

Baskin SM, Lipchik GL, Smitherman TA (2006) Mood and anxiety disorders in chronic headache. Headache J Head Face Pain 46(s3):S76-S87

Blaauw BA, Dyb G, Hagen K, Holmen TL, Linde M, Wentzel-Larsen T, Zwart J-A (2015) The relationship of anxiety, depression and behavioral problems with recurrent headache in late adolescence-a Young-HUNT follow-up study. J Headache Pain 16(1):10

Bollen KA (2014) Structural equations with latent variables. Wiley, New York

Byrne BM (2013) Structural equation modeling with AMOS: basic concepts, applications, and programming. Routledge, New York

Chan DW (1995) Depressive symptoms and coping strategies among Chinese adolescents in Hong Kong. J Youth Adolesc 24(3):267-279

Cheung GW, Rensvold RB (2002) Evaluating goodness-of-fit indexes for testing measurement invariance. Struct Equ Model 9(2):233-255

Compas BE, Connor-Smith JK, Saltzman H, Thomsen AH, Wadsworth ME (2001) Coping with stress during childhood and adolescence: problems, progress, and potential in theory and research. Psychol Bull 127(1):87

Ebata AT, Moos RH (1991) Coping and adjustment in distressed and healthy adolescents. J Appl Dev Psychol 12(1):33-54

Gentili C, Panicucci P, Guazzelli M (2005) Psychiatric comorbidity and chronicisation in primary headache. J Headache Pain 6(4):338-340

Gladstein J (2004) Children and adolescents with chronic daily headache. Curr Pain Headache Rep 8(1):71-75

Goodman R (2001) Psychometric properties of the strengths and difficulties questionnaire. J Am Acad Child Adolesc Psychiatry 40(11):1337-1345

Goodman R (2011) Information for researchers and professionals about the strengths and difficulties questionnaires. Youth in mind. http://www. sdqinfo.org. Accessed 2 Dec 2015

Guidetti V (2002) Psychiatric comorbidity in chronic daily headache: pathophysiology, etiology, and diagnosis. Curr Pain Headache Rep 6(6):492-497

Guidetti V, Galli F, Cerutti R, Fabrizi P (2000) Chronic daily headache in developmental ages: diagnostic issues. J Headache Pain 1(1):S89-593

Hirschfeld G, von Brachel R (2014) Multiple-group confirmatory factor analysis in R-A tutorial in measurement invariance with continuous and ordinal indicators. Prac Assess Res Eval 19(7):2
Holen S, Lervåg A, Waaktaar T, Ystgaard M (2012) Exploring the associations between coping patterns for everyday stressors and mental health in young schoolchildren. J Sch Psychol 50(2):167-193

Hooper D, Coughlan J, Mullen M (2008) Structural equation modelling: quidelines for determining model fit. J Bus Res Methods 6:53-60

Innamorati M, Pompili M, Erbuto D, Ricci F, Migliorati M, Lamis D, Amore M Girardi P, Martelletti P (2015) Psychometric properties of the stagnation scale in medication overuse headache patients. J Headache Pain 16(1):1-9. doi:10.1186/1129-2377-16-2

Jorgensen RS, Dusek JB (1990) Adolescent adjustment and coping strategies. J Pers 58(3):503-513

Krogh A-B, Larsson B, Linde M (2015) Prevalence and disability of headache among Norwegian adolescents: a cross-sectional school-based study. Cephalalgia, 0333102415573512

Lanzi G, Zambrino C, Ferrari-Ginevra O, Termine C, D’arrigo S, Vercelli P, De Silvestri A, Guglielmino C (2001) Personality traits in childhood and adolescent headache. Ceph Int J Headache 21(1):53-60

Lazarus RS, Folkman S (1984) Stress, appraisal, and coping. Springer, New York

Lipton RB, Manack A, Ricci JA, Chee E, Turkel CC, Winner P (2011) Prevalence and burden of chronic migraine in adolescents: results of the chronic daily headache in adolescents study (C-dAS). Headache J Head Face Pain 51(5):693-706

Martin PR, Theunissen C (1993) The role of life event stress, coping and social support in chronic headaches. Headache J Head Face Pain 33(6):301-306

Mathai J, Anderson P, Bourne A (2004) Comparing psychiatric diagnoses generated by the strengths and difficulties questionnaire with diagnoses made by clinicians. Aust N Z J Psychiatry 38(8):639-643

Meade AW, Johnson EC, Braddy PW (2008) Power and sensitivity of alternative fit indices in tests of measurement invariance. J Appl Psychol 93(3):568592. doi:10.1037/0021-9010.93.3.568

Murberg TA, Bru E (2005) The role of coping styles as predictors of depressive symptoms among adolescents: a prospective study. Scand J Psychol 46(4):385-393

Olesen J, Steiner T (2004) The international classification of headache disorders, 2nd edn (ICDH-II). J Neurol Neurosurg Psychiatry 75(6):808-811

Osborne JW (2011) Best practices in using large, complex samples: the importance of using appropriate weights and design effect compensation. Prac Assess Res Eval 16(12):7

Pallant J (2010) SPSS survival manual: a step by step guide to data analysis using SPSS, 4th edn. Allen and Unwin, Crows Nest

Pompili M, Serafini G, Di Cosimo D, Dominici G, Innamorati M, Lester D, Forte A, Girardi N, De Filippis S, Tatarelli R, Martelletti P (2010) Psychiatric comorbidity and suicide risk in patients with chronic migraine. Neuropsychiatr Dis Treat 6:81-91

Powers SW, Gilman DK, Hershey AD (2006) Headache and psychological functioning in children and adolescents. Headache J Head Face Pain 46(9):1404-1415

Pratt CC, Schmall V, Wright S, Cleland M (1985) Family relations. Fam Health Care 34(1):27-33

Puca F (2000) Psychological and social stressors and psychiatric comorbidity in patients with migraine without aura from headache centers in Italy: a comparison with tension-type headache patients. J Headache Pain $1(1): 17-25$

Rollnik JD, Karst M, Fink M, Dengler R (2001) Coping strategies in episodic and chronic tension-type headache. Headache J Head Face 41(3):297-302

Seiffge-Krenke I (2000) Causal links between stressful events, coping style, and adolescent symptomatology. J Adolesc 23(6):675-691

Seshia SS, Wang S-J, Abu-Arafeh I, Hershey AD, Guidetti V, Winner P, WöberBingöl Ç (2010) Chronic daily headache in children and adolescents: a multi-faceted syndrome. Can J Neurol Sci 37(6):769-778

Statistics Norway, 2015. https://www.ssb.no/statistikkbanken. Accessed 2 Dec 2015

Steiner TJ, Martelletti P (2007) Aids for management of common headache disorders in primary care. J Headache Pain 8(1):2

Steiner T, Birbeck G, Jensen R, Katsarava Z, Stovner L, Martelletti P (2015) Headache disorders are third cause of disability worldwide. J Headache Pain 16(1):1-3. doi:10.1186/s10194-015-0544-2

Stovner L, Zwart JA, Hagen K, Terwindt G, Pascual J (2006) Epidemiology of headache in Europe. Eur J Neurol 13(4):333-345

Stovner L, Hagen K, Jensen R, Katsarava Z, Lipton R, Scher A, Steiner T, Zwart JA (2007) The global burden of headache: a documentation of headache prevalence and disability worldwide. Ceph Int J Headache 27(3):193-210 
Van Roy B, Veenstra M, Clench-Aas J (2008) Construct validity of the five-factor strengths and difficulties questionnaire (SDQ) in pre-, early, and late adolescence. J Child Psychol Psychiatry 49(12):1304-1312

Verri A, Proietti CA, Galli C, Granella F, Sandrini G, Nappi G (1998) Psychiatric comorbidity in chronic daily headache. Ceph Int J Headache 18:45

Wang S-J, Juang K-D (2002) Psychiatric comorbidity of chronic daily headache: impact, treatment, outcome, and future studies. Curr Pain Headache Rep 6(6):505-510
Wang S-J, Juang K-D, Fuh J-L, Lu S-R (2007) Psychiatric comorbidity and suicide risk in adolescents with chronic daily headache. Neurology 68(18):1468-1473

Wittrock DA, Myers TC (1998) The comparison of individuals with recurrent tension-type headache and headache-free controls in physiological response, appraisal, and coping with stressors: a review of the literature. Ann Behav Med 20(2):118-134

\section{Submit your manuscript to a SpringerOpen ${ }^{\circ}$ journal and benefit from:}

- Convenient online submission

- Rigorous peer review

- Immediate publication on acceptance

- Open access: articles freely available online

- High visibility within the field

- Retaining the copyright to your article

Submit your next manuscript at $\downarrow$ springeropen.com 